\title{
MONEDA Y BANCA ENTRE LOS AÑOS 1863 Y 1936 EN COLOMBIA*
}

Carlos Andrés González León

Recibido: Abril 30 de 2014 Aprobado: Mayo 30 de 2014

\section{RESUMEN}

A partir de la pregunta sobre el modelo de banca en Colombia se revisan dos momentos paradigmáticos en su consolidación: el modelo de banca libre que operó hacia finales del siglo XIX, y el modelo de banca intervenida. Para lo cual se muestra cómo el marco institucional desde el derecho se ha explicado recurriendo a la revisión dogmática tradicional que escinde el estudio de lo público de lo privado en un período en que la formación de la estructura institucional se encontraba sometida al vaivén de las tensiones entre los discursos del poder y su reparto. Para lograr el objetivo se hace un recorrido histórico al proceso de formación de los modelos de banca con el fin de identificar problemas que ofrecen sus categorías.

Palabras Claves: derecho privado, derecho público, modelo de banca, banca libre, banca intervenida, intervención estatal, federalismo, centralismo, organizaciones, instituciones, cambio institucional.

\section{MONEY AND BANKING BETWEEN 1863 AND 1936 IN COLOMBIA}

\footnotetext{
* Este articulo constituye un avance producto de la investigación de tesis doctoral sobre "Concepciones de nuevas dogmáticas en el Derecho Privado en torno al patrimonio autónomo fiduciario.", adscrita al programa de Doctorado de la Universidad Libre - Seccional Bogotá.

** Estudiante de Doctorado en Derecho en la Universidad Libre de Colombia, Seccional Bogotá. Abogado. Especialista en Derecho Comercial; Especialista en Ciencia Política y en Derecho procesal Civil; Maestro en Administración del Instituto Tecnológico de Estudios Superiores de Monterrey en convenio con la Universidad Autónoma de Bucaramanga. Profesor Asociado de tiempo completo de la Universidad Autónoma de Bucaramanga. Correo electrónico: cgonzale@unab.edu.co
} 


\section{ABSTRACT}

This article focuses on the question about the banking model in Colombia, and reviews two of its paradigmatic expressions in the process of its consolidation: the free banking model that operated by the end of the XIX century and the intervened banking model. The paper points out how the institutional framework has been explained from the legal perspective using the traditional dogmatic review that separates the study of public and private sectors in a period in which the institutional structure was subjected to tensions between the discourses of power and its distribution. To achieve this objective, it is carried out a historical revision of the process of formation of banking models, which enables to identify the problems arisen by their categories.

Key words: Private Law, Public Law, Banking model. Free banking, Intervened Banks, State intervention, Federalism, Centralism, organizations, institutions, institutional change.

\section{MOEDA E BANCO ENTRE 1863 E 1936 NA COLÔMBIA}

\section{RESUMO}

Modelo de banco gratuito que operava no final do século XIX e operado modelo de banco: a partir da pergunta sobre o modelo de banco na Colômbia dois momentos de paradigma na sua consolidação são revistos. Para que mostra como o quadro institucional da direita foi explicado usando a revisão dogmática tradicional, que se unirá ao estudo do público e do privado, em um período em que a formação da estrutura institucional foi submetida à influência de tensões entre os discursos de poder e sua distribuição. Para alcançar o objetivo de um processo histórico de formação dos modelos bancários, a fim de identificar problemas é oferecido categorias.

Palavras chaves: Direito Privado. Direito Público. Modelo Banking. Bancário gratuito. Intervenção do Estado. Federalismo. O centralismo. Organizações, Instituições, Mudança Institucional.

\section{INTRODUCCIÓN}

El trabajo que a continuación se presenta estudia a partir de la revisión de fuentes secundarias, elementos y categorías que permitan reconstruir la historia jurídica de la moneda y la banca en el período comprendido entre 1863 y 1936 en Colombia, por lo que los dos aspectos deben explicarse 
en forma previa para la escogencia metodológica de ese estudio. El primero es el tránsito constitucional. El año 1863 está marcado por la formación de la Constitución de Rionegro que da vida a los Estados Unidos de Colombia, esta Constitución, vigente por 23 años, de ideario liberal y de naturaleza federal, trae en su seno los problemas de reparto regional del poder y riqueza. Posteriormente y durante este mismo período, se promulga la Constitución de 1886 de carácter centralista y conservadora en su concepción, constitución que da vida a la República de Colombia, y que va a estar vigente por 95 años.

El final del siglo XIX en Colombia está marcado, entonces, por una serie de hechos trascendentales: una nueva Constitución, guerras civiles, dentro de las cuales se destaca para nuestro estudio la denominada Guerra de los Mil Días, y el intento de unificar la moneda a través de una banca nacional o central (como banco emisor) asunto que sólo se va a lograr en forma plena hasta 1923 con las normas expedidas por el Congreso de la República y su entrada en vigencia, normas que recogen las recomendaciones de la Misión Kemmerer sobre organización económica y que, para el caso de la unificación monetaria, requirió tratamiento constitucional previo, Acto Legislativo de 1910, en relación con la emisión de moneda. Finalmente, en el año 1936, con el acto legislativo $\mathrm{N}^{\circ}$. 1, se reforma la Constitución nacional de 1886 haciendo cambios poderosos en materia de derechos fundamentales y garantías constitucionales de libertad de empresa e intervención, con derroteros especiales en el tema de la banca.

En segundo lugar, este trabajo revisa el contexto de libertad bancaria durante el siglo XIX frente al entorno de cambio que aparece en los primeros años del siglo XX en Colombia; con ello se pretende enlazar el tema constitucional con lo que podríamos denominar "la vida privada" en asuntos mercantiles. Revisión que no se suele hacer desde lo jurídico en conjunto, pues casi siempre se desliga el análisis de lo constitucional de las estrategias enmarcadas en el contexto del mundo de los negocios y del derecho privado en esta materia, reduciéndose solo a presentar un esquema independiente de orden dogmático en cada campo. Por las razones enunciadas por "moneda y banca", para los efectos de este estudio, se debe entender: a) el orden de la práctica bancaria general durante el periodo de análisis $\mathrm{y}, \mathrm{b}$ ) el tránsito de lo constitucional frente a la ordenación de banca central como banca de emisión y dirección de política monetaria junto con la estructura del sistema financiero a efectos de su intervención y funcionamiento. Por ello, desde el punto de vista metodológico, se consideran en su conjunto dos temas: 1) Moneda y 
Banca durante en los Estados Unidos de Colombia (1863-1886) 2) Moneda y banca en Colombia. Los presupuestos del orden financiero en Colombia durante los primeros años del siglo XX: una revisión del entorno constitucional y legal; y finalmente, procurará ofrecer unas conclusiones generales. Esta revisión se soporta en dos marcos teóricos, en los trabajos de Douglass C. North sobre instituciones y cambio institucional (North, 2006) y en los trabajos de Giovanni Tarello, en particular los contenidos en su obra sobre cultura jurídica y política del derecho (Tarello, 1995). Siempre que se revisa la historia constitucional y la historia del derecho privado, hay una preocupación metodológica por describir en forma detallada los contenidos normativos de cada uno de los estatutos o dispositivos, haciendo acopio y relación principal de leyes, códigos, actas y disposiciones constitucionales, en función de una visión exegética y explicativa de las mismas, en donde se pierden de vista los actores, sus estrategias y los contenidos ideológicos profundos que hay tras esas prescripciones normativas. Explica Tarello que las "[...] estructuras organizativas complejas, los derechos codificados y los códigos con sus nombres técnicos y con su “cultura", están dotadas de un elemento ideológico, de una filosofía operativa que las idea, las promueve, las percibe, las reflexiona" (1995, p.40). Por lo que, reconstruir la historia jurídica no solo guarda relación con la enumeración sistemática de constituciones, leyes, decretos $\mathrm{y}$ resoluciones, ni con su revisión dogmática en la que el derecho se explica por sí mismo, sino que exige reconocer cuáles son las organizaciones (estructuras de poder) que pueden marcar las estrategias a partir de su comprensión del entorno y de sus limitaciones para la acción, estrategias que implican necesariamente la adopción de reglas de juego en dos sentidos: la adecuación de las acciones y de las estrategias de los actores hacia el uso de las reglas de juego como limitaciones institucionales, bien sea abocándose a su cumplimiento o a su elusión o uso estratégico, o promoviendo su cambio; cambio institucional que puede significar el fortalecimiento de los intereses de los actores u organizaciones y por lo tanto, la búsqueda de la eficiencia particular, así como también, cambios institucionales que busquen la eficiencia, y por lo tanto el cumplimiento de la aspiración social hacia la equidad y la justicia. Es por esta razón que se siguen las distinciones analíticas que hace North sobre instituciones, organizaciones y cambio institucional, pues permiten ahondar en una visión más completa de los dispositivos del derecho público y de las estrategias que los actores (organizaciones, en términos de North) usan adecuar su acción y lograr sus intereses. En este sentido aparece con todo su peso la formulación teórica de North al indicar que si bien "[L] as instituciones existen y reducen las incertidumbres propias 
de la interacción humana", esto no significa que "[...] las instituciones sean eficientes" (North, 2006, p.41).

\section{MONEDAY BANCA DURANTE EN LOS ESTADOS UNIDOS DE COLOMBIA (1863-1886)}

\subsection{Antecedentes}

Una de las dificultades que encuentra quien estudia el periodo indicado en este aparte, es el estudio de las mentalidades, es decir, de cómo pensaban los hombres y mujeres de su tiempo evidenciado por el hecho de que el siglo XIX marca el tránsito de lo colonial hacia la Independencia y en consecuencia hacia la formación de la República, dificultad que se aumenta cuando se integra el análisis del entorno político y económico para la nueva organización estatal, que aparece entrelazado con el ámbito jurídico de dos formas especiales: a) de una parte un tránsito constitucional permanente, acompañado de frecuentes guerras civiles de orden regional o de orden nacional, muy apegadas a lenguajes de poder (con idearios liberales o/y conservadores radicales) que se mezclaban con el ideario y la ortodoxia religiosa de la moral cristiana profesada por la iglesia católica y, b) un mundo que se abre en el campo de los negocios a partir de las ideas del liberalismo manchesteriano de libertad de mercados, con provincias o Estados independientes y autónomos, con una organización federal, ideas que se identificaban comúnmente con quienes seguían lo que podría denominarse como corriente liberal, en oposición a las ideas conservadoras que propugnaban un modelo de economía proteccionista con un estado central fuerte y de carácter interventor .

Desde la Independencia y hasta la mitad del siglo XIX, cuando los idearios liberales quedan plasmados en estatutos constitucionales y legales, y son puestos en la práctica mercantil, se hizo evidente que la administración Estatal debía cambiar su estilo y salir de las costumbres coloniales, en la medida en que se siguieron conservando formas del sistema de rentas de la Colonia durante las repúblicas posteriores, ejemplos de lo cual son el tributo indígena, el diezmo y el estanco. Es decir, al lado de los tránsitos constitucionales y de la organización de la sociedad posindependentista, debía venir una concepción de la hacienda pública nueva que permitiera mantener la confianza pública en las instituciones y que lograra pagar los costos del Estado, fomentando a su turno la riqueza individual y nacional. Un ejemplo de ello es la opinión de Florentino González (Memoria de Hacienda al Congreso, 1847). Al 
indicar que la pobreza del Estado se debe a que no se ha fomentado de manera suficiente la formación de la riqueza individual, sustento natural de la riqueza pública, para introducir como política de mercado el libre cambio y adicionalmente la producción para la exportación (González, 1985-1986).

Es así como durante el primer gobierno de Tomás Cipriano de Mosquera se instaura la libertad de comercio con el libre cambio sancionado con la Ley del 14 de Julio de 1847, pues se reducían los "derechos de importaciones". . Este hecho resulta de trascendental importancia para el tema de la banca, porque el libre cambio y el comercio exterior que resultaba de la actividad mercantil iba de la mano del ideario liberal, de la concepción de Estado (federal con provincias o estados autónomos) y, por lo tanto, de la necesidad de promover sistemas de banca que permitieran su acción de manera libre, bajo el supuesto de que los mercados se autorregulan, haciendo innecesaria la presencia de la participación directiva del Estado en el sistema financiero y comercial. Esto último trae como consecuencia que la discusión sobre libertades económicas en materia financiera no requiera determinación de políticas públicas en materia de manejo del crédito y la moneda y que por lo tanto se requiera una banca central de emisión. Debe observarse que esta idea liberal coincide con el hecho de que el Estado debe financiarse acrecentando las arcas privadas de donde su sistema hacendístico se nutre con cargas fiscales (concebidas en un esquema de gradualidad que supone que a mayores ingresos debe haber mayor carga impositiva a pagar), con nuevos sistemas de contabilidad más seguros y sanos, que superan los sistemas de ingreso que se usaban en la Colonia y que continuaron aplicándose durante la primera mitad del siglo XIX. De alguna forma, es un país que empieza a adaptarse a su nueva realidad republicana.

En el importante estudio de SAFFORD sobre las interpretaciones socioeconómicas de la política en la Colombia del siglo XIX, en que se examinan las distintas líneas de pensamiento e interpretación de la historia económica que los investigadores e historiadores han tenido sobre este período del siglo XIX, expresa en torno al tema del ideario liberal y conservador: "La integridad y la cohesión de una interpretación que considera los inicios de los años 1850 como una revolución liberal burguesa llevada a cabo por una clase social emergente (...)" indica que: 
(...) los años 1850 pueden ser considerados como un punto clave en la transición de Colombia de un orden "feudal" tradicional a un capitalismo burgués (...). O sea, han considerado la reforma liberal de mediados de siglo como una revolución capitalista burguesa, protagonizada por una clase comercial emergente en conflicto con los antiguos terratenientes tradicionales dominantes, a los que llega a vencer. Todos estos autores identifican también a la clase comercial emergente con el partido liberal y a los terratenientes tradicionales con el partido conservador. (Safford, 1985-1986, p.100).

\subsection{La Constitución de Rionegro y el modelo de Banca Libre}

La Constitución de Rionegro (1863) fue la expresión del ideario liberal decimonónico, de hecho en la Convención estuvieron los principales líderes del liberalismo de la época ${ }^{2}$. En un medio cargado de conflictos religiosos, políticos y de guerras civiles, aparece una Constitución que consigna la inviolabilidad de la vida humana, la libertad individual, la seguridad personal, la propiedad, la libertad de imprenta y de información, la libertad de empresa, la posibilidad de tener armas y comerciarlas, la libertad de movilidad entre otros derechos, obrando con fundamento en la autorización del pueblo. (Constitución Política de los Estados Unidos de Colombia. Capítulo Segundo. Bases de la Unión. Sección Segunda. Garantía de los derechos Individuales), lo cual imprimía un matiz de contradicción en el panorama nacional. El sistema federal adoptado permitía que los Estados tuvieran plena autonomía en la expedición de Códigos y de sus asuntos internos, (forma de elección y organización administrativa, conformación de ejércitos entre otros).

Kalmanovitz en estudio sobre el tema (S.F. p.5). Considera que el esquema Federal que se ofreció durante la vigencia de los Estados Unidos de Colombia, no contó con adecuadas instituciones ni con un parlamentarismo maduro que permitiera conciliar las diferencias en una adecuada salida negociada, pues de hecho sugiere, citando en su avance a Barry Weingast ${ }^{3}$, que los sistemas federales incentivan por su

2 Entre ellos se encontraban Tomás Cipriano de Mosquera, Aquileo Parra, Camacho Roldán, Eustorgio Salgar y José Hilario López, entre otros.

3 Las condiciones que considera el autor para que el federalismo contribuya al desarrollo económico consisten en que: "Existe una jerarquía de gobiernos con un área delineada de autoridad para cada cual. El gobierno subnacional obtiene autoridad primaria sobre la economía local. El gobierno nacional tiene la autoridad para vigilar el desarrollo de un mercado común o interno. Tanto el gobierno nacional como el local obtienen restricciones presupuestales fuertes. La autoridad política está asignada en forma institucional e impide que el gobierno nacional atropelle a los gobiernos sub-nacionales.” (Kalmanovitz, S.F.p.5) 
naturaleza el desarrollo económico, y que a pesar del entorno constitucional, la situación que de hecho vivía el país se encontraba amarrada a una idea en la que:

(...) el sistema político centralista colombiano, basado en el derecho divino y en la noción de estado confesional, no contó con las instancias de negociación para desactivar las luchas fratricidas que arruinaron al país a finales del siglo XIX y que han reaparecido en la mitad y a fines del siglo XX para frenar su desarrollo económico. (Kalmanovitz, S.F. p.2).

En términos de la Banca, a partir del año 65, los Estados Unidos de Colombia se incorporan en lo que se conoce como Banca Libre; Echeverri la define como: "(...) un sistema monetario en el cual la banca privada, en forma competitiva, emite pasivos a la vista que se pueden redimir por una moneda mercancía, definida mas no controlada por las autoridades.” (1994, p. 305). El sistema de Banca Libre es lo opuesto al sistema de control con una Banca Central que regula. El sistema de banca libre supone una serie de condiciones ambientales que, indica Echeverri, se cumplían durante el periodo de análisis: libertad de movimiento y de capitales, marco legal que fomenta la libertad de empresa, ausencia de regulación bancaria y un sistema judicial que contribuya y fomente el cumplimiento de los acuerdos.

Bajo ese espectro el mercado controla la moneda del país, los bancos están autorizados a expedir moneda siguiendo la clásica lógica mercantilista en la cual la emisión de deuda del banco privado se encuentra respaldada por las reservas en oro y plata que guarda en sus arcas y por lo tanto su éxito se estimula con la competencia en el mercado, asunto que depende de su credibilidad en términos de cumplimiento y manejo de un adecuado régimen prudencial ${ }^{4}$.

Por esta razón los principios económicos liberales en que se inspiraba la Constitución de 1863 eran perfectos para el desarrollo de este tipo de banca al permitir la libertad de empresa, movilidad y comercio, junto con un poder central pequeño en relación con el amplísimo marco de poderes conferidos a las regiones. Este es un periodo de una rica formación de bancos, cajas de ahorros y casas comerciales y bancarias.

4 Para el presente trabajo debe entenderse por régimen prudencial a todas aquellas medidas que llevan a administrar de manera adecuada los recursos monetarios de ahorro y crédito, es decir evitando el riesgo de inversiones que conlleven problemas futuros de iliquidez o de insolvencia de los intermediarios, que pongan en tela de juicio su operación y que las lleven al cierre o al control de las autoridades financieras. 


\subsection{La Regeneración y el Gobierno de Rafael Núñez. El cambio de modelo de Estado. EI Banco Nacional}

Se ha denominado Regeneración al movimiento político conservador entre 1896 y 1904 influenciado por el pensamiento conservador francés del Segundo Imperio, siendo el centralismo, autoritarismo y religión católica sus reglas básicas para el orden social. Este pensamiento es el que va a impregnar la Constitución de 1886, cuyos artífices fueron Rafael Núñez y el ultra conservador Miguel Antonio Caro (Malagón, 2006).

Podría indicarse que el buen rumbo del mercado libre y de su modelo de banca, se desbalancea con la llegada al gobierno de Rafael Núñez, quien promueve la formación del Banco Nacional (creado el 1 de enero de 1881) y la unidad monetaria en contravía de las formulaciones de la banca libre, pues esto supone un control central de la moneda y una moneda única. La Ley 39 de 1880, autoriza a Núñez para crear el Banco Nacional tratando de aliviar el déficit fiscal adquirido durante su gobierno, para terminar en 1887 prohibiendo totalmente la emisión de nuevos billetes por los bancos.

ECHEVERRI en indica que desde 1881 el déficit fiscal creció por las medidas de Núñez de crear empleos públicos, aumentar sus salarios y aumentar la obra pública, esto llevo a que entre “(...) 1881-1882, los ingresos fueron $\$ 5,5$ millones, mientras los egresos fueron $\$ 9$ millones; en el siguiente (1883-84), los ingresos aumentaron a $\$ 6$ millones, pero las salidas prácticamente se duplicaron y fueron $\$ 16$ millones. Estos déficit permanentes continuaron aumentando y cuando terminó la guerra civil 1884-85 se hicieron insostenibles. Cada año eran financiados con nuevas emisiones de billetes del Banco Nacional.” (1994, p, 312).

El caso de Rafael Núñez es de particular importancia, porque Núñez hizo parte de los gobiernos de Tomás Cipriano Mosquera y comulgaba con el ideario liberal del cual se rodeó hasta iniciar sus administraciones, e incluso firmó el decreto de manos muertas de 1861, pero, al llegar al poder, sus ideas económicas y políticas eran de naturaleza conservadora y en consecuencia contenían en su seno el objetivo de reorientar el orden institucional, convirtiéndose, Núñez, como bien lo sugiere el profesor Henao, en "el anticonstituyente de la carta magna del liberalismo radical decimonónico" (1992, p.27). De hecho, Núñez llega al poder gracias al apoyo liberal, pero una vez iniciada su administración propició el aumento del Estado, la inversión en obra, aumentó salarios de los nuevos funcionarios e impulsó el centralismo, que va a quedar plasmado en la 
Carta Constitucional de 1886, siendo su lema el de un fuerte centralismo político y una descentralización administrativa.

Los nueve Estados soberanos de los Estados Unidos de Colombia, pasaron bajo el nuevo orden constitucional a ser departamentos dependientes del control central, por lo que perdieron la amplia autonomía que les diera la Constitución Federal de 1863, que suponía que los Estados federados podían darse su organización administrativa, dictar sus leyes, tener su propio régimen judicial y de hacienda y organizar sus ejércitos, siendo el Estado federal, bajo esta perspectiva, un cohesionador de las políticas generales del Estado y un representante ante la comunidad internacional, sistema que permitió el modelo de banca libre y la libertad de comercio en el país.

El centralismo en consecuencia aumentó el nivel de gasto público como se hizo evidente durante todo el gobierno de Núñez, asunto que este resolvió con emisiones de moneda de curso legal forzoso y sin respaldo, que evidentemente causó el rechazo de los banqueros y comerciantes, quienes padecieron los costos de un nuevo régimen monetario obligatorio lesivo frente al pago de sus obligaciones en moneda extranjera respaldadas en oro (Alviar, 1988).

Sobre el particular explica Safford:

Las medidas económicas de Núñez, especialmente la creación del Banco Nacional emisor, chocaron con los intereses de la élite comercial de la nación. Críticos posteriores han solido subrayar el hecho de que esta innovación tuvo que hacer frente a la resistencia de los comerciantes y los banqueros, porque interrumpía su casi exclusivo control sobre el establecimiento de crédito (Liévano Aguirre, 1960, p.300). Esto puede haber sido cierto. Sin embargo, también es cierto que estos individuos tenían razones para temer a un banco emisor controlado por el gobierno. Podían sospechar una probable mala administración gubernamental y una profusión desbordada del nuevo numerario. Mientras que un circulante depreciado tuviera que ser aceptado en pago por las deudas, los comerciantes y los banqueros tendrían que enfrentar la necesidad de aceptar un pago en papel moneda devaluado por deudas contraídas en circulantes más fuertes. Además, el nuevo papel moneda estatal introducía otro elemento de 
incertidumbre en un ambiente de negocios de por sí poco estable, haciendo que el contraer obligaciones a largo plazo, especialmente en moneda fuerte europea fuera algo problemático. Ya sea que se tenga una opinión negativa o benévola de la élite comercial colombiana, el hecho es, sin embargo, que le hizo frente al Banco Nacional y a su papel moneda. Cuando los comerciantes y los banqueros no oficiales se rehusaron a proporcionar un respaldo de capital al Banco nacional y a aceptar los billetes de este por su valor nominal, Núñez hizo que fueran recibidos obligatoriamente (1885) y en 1887 prohibió a los bancos no oficiales la emisión de billetes. (Safford, 1985-1986, p.119).

Con dos decretos de la época se puede constatar la reacción de la administración Núñez al modelo de banca libre: el Decreto 479 de 1899, expedido el 16 de octubre, proferido por los problemas de orden público, y el Decreto 520 de 1899, de 28 de octubre, para atender los gastos de la guerra. El primero indica que si estalla la rebelión se imprimirán billetes necesarios para dejarlos en disposición del Ministerio del Tesoro, con el fin de conjurarla. El segundo para atender gastos de guerra autoriza a la Junta de Emisión emitir las cantidades de billetes necesarios para conjurar el problema de orden público. De hecho, esta práctica de emitir sin respaldo, nunca antes vista en la historia nacional, conllevó que el inicio del siglo XX arribara con hiperinflación (la mayor inflación en la historia del país) pues el gobierno nacional se comprometió a reducir el nominal circulante a 12 millones, pero pasó al finalizar la guerra de los mil días a 831 millones de pesos. Las cifras en términos de inflación y tasa de cambio sufrieron drásticos cambios: inflación de: " $0 \%$ en 1896 y 1898 se incrementó a $15.2 \% \quad 1899,66 \%$ en 1900 y 389 en $1901 \%$ y promedió $120 \%$ hasta 1903 . La tasa de cambio nominal con respecto a la libra esterlina aumentó de 2.4 a 97,17 pesos por libra entre 1896 y 1903" (Sánchez, 1994, p.55). El Banco Nacional entra en liquidación en 1896, liquidación que ordena el Decreto 195 de 15 de abril (Romero, 1987).

Debe recordarse que el siglo XIX termina con la adopción de una nueva carta constitucional. Esta carta, como ya se indicó, plasmaba el ideario conservador y se sostenía con el lema de centralización política, descentralización administrativa. Esta Constitución en relación con el tema económico no contenía disposiciones especiales (ya estaban las autorizaciones legales y el Banco nacional), por lo que la carta contenía una forma de intervención general institucional a través de la división y 
separación del poder público en sus órdenes legislativo, ejecutivo y judicial, sin que hubiera normas especiales sobre control y dirección de la economía, menos aún sobre la banca. En este sentido, si se observa la historia del Banco Nacional, el control era de naturaleza legal.

\section{PRESUPUESTOS DEL ORDEN FINANCIERO EN COLOMBIA DURANTE LOS PRIMEROS AÑOS DEL SIGLO XX}

Como ya se evidenció con la cifras sobre déficit fiscal durante el gobierno de Núñez (Echeverri, 1994). La administración central provocó un crecimiento del aparato estatal, un mayor nivel de gasto (con el adicional incremento en los salarios de los servidores públicos) y lo que resultó más grave en términos de seguridad y rentabilidad de los mercados, frente a la confianza pública en el sistema nuevo, obligó a través de un sistema proteccionista y de banca central a aceptar los billetes impresos sin respaldo que financiaban la guerra civil y el aumento del gasto público, sin contar con el encarecimiento de las obligaciones en tipo de cambio real de la época con moneda fuerte extrajera, particularmente con la libra esterlina. La consecuencia natural de todo lo anterior fue el traer el rechazo y la desconfianza en el manejo público de la emisión de dinero (que hasta ahora había quedado, con la banca libre en cabeza de los bancos privados y de las casas comerciales), e independientemente de la consideración de las ventajas o desventajas del sistema, alejó la posibilidad de un manejo unificado del circulante monetario y de una administración central fuerte que consolidara el ideario conservador que proponían. Es decir que el siglo XX empezó con un país afectado por la hiperinflación y por una tasa de cambio elevada que hizo muy duros los pagos de la deuda privada externa, en medio de un sistema irresponsable de emisión de dinero con curso legal forzoso.

El intento de formar un banco único encargado de la emisión se va a volver a repetir en 1905, durante el gobierno de Reyes, pero va a tener el mismo fracaso, pues no obtiene el respaldo de los comerciantes y se duda del control serio sobre procesos de emisión. En 1909 el Banco Central de Colombia, recién formado se liquida. Este banco central:

(...) manejado por Pepe Sierra, el cual no pudo aglutinar los más importantes capitales existentes en el país, encontrando dificultades hasta para ser reconocido como garante de los préstamos que en varias instancias reclamó Reyes del comercio y de la banca de la capital. El banco se gerenció con criterios muy conservadores, a pesar de la reputación de 
gran especulador que pesaba sobre Pepe Sierra, y fue el instrumento utilizado por el gobierno para recoger el papel dinero de curso forzoso, desvalorizado durante la contienda, y reemplazarlo por la nueva unidad monetaria. Se trataba nada menos que de devolver la confianza que se había perdido durante la guerra, según lo demostraba la práctica desaparición de la moneda metálica, convertida en medio de atesoramientos, y también lo exiguo de las operaciones crediticias. (Kalmanovitz, 2003, p.283).

Este problema de desconfianza pública en una banca central con manejo de la emisión, provocado principalmente por el uso indiscriminado y sin reglas claras de los procesos de emisión y acuñamiento de moneda, hace necesario que se incluya en la agenda de reforma de la Constitución de 1886, por lo que el Acto Legislativo $\mathrm{N}^{\circ} .3$ de 1910, artículo 7, entre otros asuntos, regla la materia así: "Queda prohibida en absoluto toda nueva emisión de moneda de curso forzoso". Texto constitucional que zanja cualquier duda sobre el uso arbitrario por la banca central de los procesos de emisión y que delata el afán por la unificación monetaria, amparado por el autoritarismo conservador.

Como resulta lógico, la pérdida de confianza pública en el sector financiero central trajo como consecuencia la demora en el restablecimiento del orden económico institucional. Solo 13 años después de esta reforma constitucional el país va a ver realizada la posibilidad de un banco emisor y de la unificación monetaria. Luego de la primera guerra mundial el sistema monetario internacional estaba totalmente desarticulado, razón por la cual se buscaba consolidar el sistema de paridades cambiarias, solucionar los problemas de déficit fiscal y formar bancas centrales independientes para procesos de unificación y dirección monetaria. Por lo que la Sociedad de las Naciones convocó a la Segunda Conferencia Económica Internacional celebrada en Génova en el año 1922, que, como explica Alviar, recomendó “[...] el retorno al patrón oro y la fundación de bancos centrales de emisión en los países en donde estos no existían, como medidas inmediatas para la reconstrucción del mundo" (Alviar, 1988, p.18).

En Colombia, la Ley 60 de 1922 ordenó contratar lo que hoy se conoce como Misión Kemmerer, grupo de análisis y estudio en asuntos económicos y fiscales, integrado por profesores norteamericanos y dirigida por Edwin Walter Kemmerer, misión que tenía por finalidad hacer recomendaciones pertinentes al país en términos de la 
organización económica y fiscal, recomendaciones que terminaron siendo acogidas y traducidas en leyes de la República, por lo que "[D]ebe en este paquete de normas legislativas la extraordinaria velocidad con que estas iniciativas fueron aprobadas por las dos Cámaras, evento que habla por sí solo del anhelo de institucionalización vigente en la época" (Garavito, 1995, pp.56 y 57).

Dentro del marco de las recomendaciones hechas por la Misión, que siguieron de cerca las directrices finales de la Segunda Conferencia Económica Internacional de Génova de 1922, se encuentran la unificación monetaria a partir de la creación de un banco central que sea a su vez autoridad monetaria, la adopción de una contabilidad nacional y de una autoridad que la controle, la creación de un ente de inspección, vigilancia y control de los mercados financieros (superintendencia bancaria, hoy financiera) y una ley de bancos, y una serie de instrumentos del orden comercial, como fueron las normas sobre instrumentos o efectos negociables. Por lo que todo el año 1923 va a resultar prolífico en expedición de leyes.

En lo que corresponde a las propuestas implícitas sobre modelo de banca, se expidieron dos leyes: a) La ley 45 de 1923 que regló la conformación de los bancos comerciales y su forma de operar, y dispuso sobre un nuevo ente de control institucional de protección de la actividad bancaria y del sistema financiero, la Superintendencia Bancaria de Colombia, como autoridad de supervisión y control de la operación privada; y, b) La ley 25 de 1923 que creó el Banco de la República de Colombia, como autoridad monetaria y del crédito, prosperando así unificación monetaria colombiana.

Tras el drástico cambio institucional operado entre los últimos años del siglo XIX y los primeros treinta años del siglo XX en Colombia, en los modelos institucionales de banca, se requiere indagar sobre cuáles fueron los centros de poder (organizaciones) desde lo público y lo privado, que llevaron a que las reglas de juego cimentadas en una concepción política que derivó en principios constitucionales liberales consignados en la Constitución federal de 1863, que promovía la libertad de mercados y la ausencia de intervención en el sistema financiero, se traslade, con la aparición de la Constitución de 1886, en un sistema central y de control. Es evidente que durante los primeros años del siglo XX los problemas derivados de la recesión económica (inflación, desempleo y cesación de pagos empresariales y personales) hacen que cambie la concepción mundial de los negocios y de la 
participación del Estado en la dirección de las economías, pero también, resulta a la par visible que el discurso y determinación de estrategias de acción se reacomodan. Asunto que debe ser explorado para reconstruir la historia del derecho nacional, pues no solo la estrategia de proteccionismo estatal que aparece consagrada en la reforma constitucional de 1936, al permitir que el Estado pueda dirigir la economía dentro del marco de la libertad de empresa, explica las estrategias y por lo tanto el influjo de los actores (organizaciones) privados en esa administración y dirección. Como lo describe North al analizar las organizaciones como grupos de individuos con identidades y objetivos comunes (partidos políticos, empresas y grupos empresariales, comunidades religiosas, por ejemplo), su consideración como elementos dentro del análisis económico, histórico (historia social del derecho), permite desvelar su papel dentro del cambio institucional (cambio de reglas de juego). Si bien las instituciones permiten establecer las limitaciones de la acción, el análisis del cambio institucional en los ámbitos jurídicos permite descubrir las estrategias de acción y de aprendizaje de las organizaciones en la formulación del uso del derecho como discurso del obrar. Esto quiere indicar que detrás de la estructura institucional (en nuestro caso, los dispositivos del derecho público, como los de derecho privado del período analizado) deviene reacomodamiento y ajuste:

[L]os individuos actúan con base en información incompleta y con modelos derivados subjetivamente que con frecuencia son erróneos; típicamente la retroalimentación de la información no basta para corregir estos modelos subjetivos. Las instituciones no son creadas por fuerza ni tampoco para ser eficientes socialmente; más bien estas instituciones, o cuando menos las reglas formales, son hechas para servir los intereses de quienes tienen el poder de negociación para idear nuevas normas. (North, 2006, p.29).

Los años que anteceden a la reforma constitucional de 1936 son convulsos en el entorno internacional: representan un periodo crítico de entre guerras, que corre a la par con la gran crisis financiera internacional enmarcada por la recesión económica occidental que inició en el año 29, y que trajo como consecuencia el cuestionamiento del ideario económico clásico y la aparición práctica del proteccionismo y de la intervención estatales como solución a la crisis, todo ello concomitante con el abandono definitivo del sistema patrón oro, luego de que, con causa en la recesión, Inglaterra y Estados Unidos dejaran de usarlo como marco de 
referencia en el año 31 tras el decrecimiento de sus reservas internacionales. Al respecto describe Alviar:

Pudiera decirse que en el mundo y en Colombia, se vivió durante los primeros años de la década del 30, por su aspecto monetario, bajo el signo de la perplejidad. ¿Sería el abandono del patrón oro, episodio de pocos años? ¿Cuál sería el camino para evitar la inflación si la cantidad del circulante no se ligaba a alguna norma o medida? ¿Y cuál sería esta norma y medida que reemplazara al oro? De otra parte, ¿Qué propósito debía cumplir un banco de emisión, si había desaparecido la finalidad suprema de su existencia que era la de convertir sus propios billetes en oro? (Alviar, 1988, p.23).

ElActo Legislativo No. 1 de 1936 estaba cimentado en buena parte en las doctrinas sociales francesas y en la obra de Leòn Dughit, (Henao, 1992). Uno de sus temas centrales fue la disposición de derechos fundamentales y garantías civiles y sociales, recogiendo estrategias normativas que van desde el reconocimiento del derecho de propiedad y sus limitaciones, la intervención del Estado en la economía, hasta los trascendentales dispositivos, para el período, sobre el derecho de reunión, huelga, trabajo, educación y libertad religiosa, entre otros.

En términos de nuestro período de análisis, este momento resulta de particular importancia, porque ordena los entornos de la política pública en materia económica, al incorporar el intervencionismo estatal en el orden constitucional y por lo tanto determina las bases de lo que será en los años siguientes, el desarrollo del contexto bancario del país.

El concepto de la intervención de 1936 se encontraba influido por las ideas de la administración científica de Taylor, en términos de la racionalización de tiempos y movimientos y de la producción en línea. La concepción básica es que el Estado busca racionalizar los recursos de su hacienda para logar sus objetivos de política pública por medio de leyes, en un contexto individualista de protección de las libertades negativas, concentradas en el derecho de propiedad y en la libertad de empresa y por lo tanto manteniendo el concepto civilista de autorregulación (artículo 1602 del Código Civil Colombiano), por lo que Estado in genere es un director de la economía. Esta incipiente visión de intervencionismo que será revisada en dos reformas constitucionales posteriores (1945 y 1968), muestra lo que será la organización estatal en 
la materia, por lo que como cierre de la revisión de elementos y categorías del período, considero que cualquier revisión que se haga sobre la intervención estatal y en particular, en términos de lo que debe ser la estructura de un sistema financiero intervenido, debe trabajar las siguientes tres categorías básicas para su análisis:

- La intervención del Estado como director general de la economía al determinar políticas públicas en el sector financiero (o en el sector intervenido de que se trate) con el fin de lograr objetivos constitucionales y legales, y objetivos plasmados en planes y programas de desarrollo, así como proteger al sector mismo, encauzándolo hacia el logro de sus metas naturales. Aquí se trata de definición de política pública general que puede quedar plasmada en leyes o en directrices tales como resoluciones de carácter general, piénsese por ejemplo en la labor de la Junta Directiva del Banco de la República, a la luz de hoy, al expedir resoluciones en su calidad de autoridad monetaria, cambiaria y del crédito.

- La intervención de la actividad privada por un Estado que inspecciona, vigila y controla de manera directa la actividad privada para que cumpla las ordenes legales y de política pública (que es el entorno natural de acción de las superintendencias).

- Finalmente, una forma menos evidente pero altamente efectiva de intervención, con un Estado que participa con el fomento en actividades de interés público contenidas en los programas de gobierno y que en algunos casos, no son rentables para la actividad privada, tales como créditos de fomento, educación, entre otros.

\section{CONCLUSIONES}

El estudio de los modelos de banca durante el período 1863-1936 ofrece varios interrogantes para efectos de la revisión de su formación legal. E1 modelo de banca libre propuesto por el esquema constitucional de 1863 permitió que casas de comercio y bancos privados manejaran la política monetaria, el crédito y en general, los medios de pago en la economía durante estos años, frente a un modelo de banca central que se introduce a finales del siglo XIX, modelo que viene acompañado de un profundo cambio institucional en el orden constitucional y que en el año 1923 supondrá la unificación monetaria y la supervisión financiera por parte de la recién creada Superintendencia Bancaria de la época. Sin embargo, 
se encuentra que al margen de los discursos de orden constitucional y legal, aparece un desdibujamiento de la historia privada y de la interpretación a partir de lo que podría llamarse "la cara de los negocios". Construir una teoría jurídica que permita descubrir el contexto ideológico de sus prescripciones formales, supone un esquema que debe observar con mayor énfasis las fuentes materiales del derecho, que en términos de North (2006), equivale a conocer cuáles son las organizaciones que tienen la posibilidad de modelar reglas de juego y por lo tanto de diseñar estrategias, reflexionarlas y llevarlas a la práctica. Descubrir los actores y sus estrategias permite que el debate se concentre no solo en la interpretación de un conjunto de reglas del derecho público o del derecho privado, es decir en la interpretación del derecho formal para derivar de él su proceso de creación, sino en la interpretación de los fenómenos sociales que forman el derecho para ordenar su alcance y contenidos. Variables como la lucha de clases y la discusión entre los órdenes comerciales y públicos del amplio período de análisis son trascendentales en la formación de estrategias que forman el derecho de la época y su teoría jurídica consolidada en normas. Como ya se indicó en estudio anterior, se muestra "un enorme vacío en términos de actores, estrategias y genética de los negocios" (Gónzalez, 2013, p.181). Que descifren los discursos, métodos y estrategias que hicieron del modelo de banca intervenida durante los primeros años del siglo $\mathrm{XX}$ viable, modelo que se consolida con las normas de intervención incorporadas en la reforma constitucional de 1936. Actores y estrategias que permiten develar cómo se lograron los ajustes institucionales dentro del sector financiero a partir de los marcos legales y constitucionales de la intervención del Estado en las tres categorías enunciadas: políticas públicas, inspección vigilancia y control y fomento, permitiendo la consolidación de negocios y formas contractuales nuevas en Colombia durante las décadas siguientes.

\section{REFERENCIAS BIBLIOGRÁFICAS}

Alviar, Oscar. (1988). Instrumentos de dirección monetaria en Colombia. Bogotá: Tercer Mundo Editores.

Colombia. Constitución Política de Colombia-1886. Recuperado de http://www.alcaldiabogota.gov.co/sisjur/normas/Norma1.jsp?i=7153

Colombia. Constitución Política de los Estados Unidos de Colombia. Recuperado de http://www.bibliojuridica.org/libros/5/2212/12.pdf 
Echeverri, Pérez Lina María. (1994). Banca Libre: La experiencia colombiana en el siglo XIX. En Sánchez, Torres (Ed). Ensayos de Historia Monetaria y Constitucional. Bogotá: Tercer Mundo Editores.

González, Carlos Andrés. (2012). Nuevas dogmáticas en el derecho privado en torno al patrimonio autónomo fiduciario. Un debate en Colombia. Revista Verba Iuris. No. 28.

González, Margarita. (1985-1986). Aspectos económicos de la administración pública en Colombia: 1820-1886. Anuario Colombiano de Historia Social y de la Cultura. Universidad Nacional de Colombia. Facultad de Ciencias Humanas. Departamento de Historia. N .13 y 14.

Henao, Hidrón Javier. (1992). Panorama del Derecho constitucional colombiano. Octava Edición. Bogotá: Temis.

Kalmanovitz, Salomón. (2003). Economía y Nación. Una breve historia de Colombia. Bogotá: Editorial Norma.

Kalmanovitz, Salomón. (2003). La idea Liberal en Colombia durante el siglo XIX. Recuperado de http://banrep.org/documentos/presentacionesdiscursos/pdf/La-idea-federal.pdf

López, Garavito, L. (1995). Intervencionismo de Estado y economía en Colombia. Segunda Edición. Bogotá: Universidad Externado de Colombia.

Malagón, Pinzón Miguel. (2006). La regeneración, la Constitución de 1886 y el papel de la iglesia católica. Revista Civilizar. No. 11. Recuperado de http://www.usergioarboleda.edu.co/civilizar/revista11/ regeneracion_constitucion.pdf

North, Douglass C. (2006). Instituciones, cambio institucional y desempeño económico. México: Fondo de Cultura Económica.

Romero, Astrid. (1987). Historia monetaria en Colombia: 1880-1905. Universidad Nacional de Colombia. Facultad de Ciencias Económicas. Departamento de Economía. Colombia.

Safford, Frank R. (1985-1986). Acerca de las interpretaciones socioeconómicas de la política en la Colombia del siglo XIX: 
Variaciones sobre un tema. Anuario Colombiano de Historia Social y de la Cultura. No. 13 y 14.

Sánchez Torres, Fabio. Compilador. (1994). Moneda y Política Monetaria en Colombia, 1920-1939. Ensayos de Historia monetaria y bancaria de Colombia. Bogotá: Tercer Mundo editores.

Tarello, Giovanni. (1995). Cultura jurídica y política del derecho. Mexico: Fondo de Cultura Económica. 